\title{
Biomaterials
}

Biomaterials 23 (2002) 2561-2568

www.elsevier.com/locate/biomaterials

\section{Blood protein adsorption onto chitosan}

\author{
Johan Benesch*,1, Pentti Tengvall \\ Applied Physics, The Department of Physics and Measurement Technology, Biology and Chemistry Linköpings Universitet, 58183 Linköping, Sweden
}

Received 14 August 2001; accepted 20 November 2001

\begin{abstract}
Chitosan was recently indicated to enhance osteogenesis, improve wound healing but to activate the coagulation and the complement systems. In the present study approximately $10 \mathrm{~nm}$ thick chitosan film were prepared on aminopropyltriethoxysilane (APTES) coated silicon. The surfaces were incubated in serum or plasma and subsequently in antibodies towards key complement and contact activation of coagulation proteins. The deposited amounts were compared with those on hydrophilic and hydrophobic silicon, APTES and IgG coated reference samples. Although large amounts of serum deposited to chitosan only a weak transient activation of the complement system and no activation of the intrinsic pathway was observed. Upon acetylation the chitosan layer became a strong activator of the alternative pathway of the complement. After incubation in human plasma anti-fibrinogen deposited onto chitosan but not onto the acetylated chitosan, a finding that may explain previous observations of procoagulant activity by chitosan. (C) 2002 Elsevier Science Ltd. All rights reserved.
\end{abstract}

Keywords: Chitosan; Surface immobilization; Serum; Contact activation; Complement activation; Ellipsometry

\section{Introduction}

Chitosan is the deacetylated form of one of the most abundant natural polymer, chitin or $\operatorname{poly}(\beta(1-4)$ GlcNAc). It is shown to enhance osteogenesis [1] and improve wound healing [2] and is used for biomaterials applications such as artificial skin, wound dressings and sutures [3]. However, it is indicated in the literature that chitosan has the capacity to activate both complement [4] and blood coagulation systems [5]. Surprisingly few, if any, studies have until now been performed to more in detail analyze the protein adsorption properties of chitosan and its capacity to activate the humoral systems in complex protein fluids such as blood serum. Hence, in the present study APTES coated surfaces were layered with chitosan and subsequently incubated in serum or plasma. Polyclonal antibodies towards a few selected serum proteins were used to detect the binding and activation of complement factors and the intrinsic pathway of coagulation proteins. The adsorbed amounts of chitosan, serum and antibodies were

\footnotetext{
*Corresponding author. Tel.: +46-013-282616; fax: +46-013288969.

E-mail addresses: johbe@ifm.liu.se (J. Benesch), pet@ifm.liu.se (P. Tengvall).

${ }^{1}$ url: http://www.ifm.liu.se/applphys/biomaterial/
}

quantified by single wavelength null ellipsometry [6]. The present results confirm that chitosan activates the complement cascade and that the activation depends on the degree of acetylation.

\section{Experimental}

\subsection{Surface preparations}

Polished silicon wafers (Okmetic, Finland) were hydrophilized by washing in deionized water (Milli-Q, $18.2 \mathrm{M} \Omega \mathrm{cm}$ ) with $30 \% \mathrm{H}_{2} \mathrm{O}_{2}$ and $25 \% \mathrm{NH}_{4} \mathrm{OH}$ in $5: 1: 1$ proportions for $5-10 \mathrm{~min}$ at $80^{\circ} \mathrm{C}$, rinsed in Milli-Q water with $30 \% \mathrm{H}_{2} \mathrm{O}_{2}, 37 \% \mathrm{HCl}$ in $6: 1: 1$ proportions for 5-10 min at $80^{\circ} \mathrm{C}$, and finally rinsed in Milli-Q water. The clean hydrophilic pieces were hydrophobized by the following procedure: the threefold rinsing in $99.5 \%$ ethanol and three rinsings in xylene was followed by a $5 \mathrm{~min}$ incubation in $1 \% \mathrm{v} / \mathrm{v}$ dichlorodimethylsilane in xylene and finally rinsed three times in xylene and in ethanol, respectively. The samples were stored in $99.5 \%$ ethanol until use. Some hydrophilic silicon pieces were rinsed in ethanol and acetone and incubated in $1 \%$ aminopropyltriethoxysilane (APTES) for $10 \mathrm{~min}$ at room conditions followed by rinsings in acetone and 
ethanol. These samples were used immediately. Most of the APTES coated pieces were incubated in a mixture of high molecular weight chitosan $(600 \mathrm{kDa}, 85 \%$ deacetylated, Fluka), $\mathrm{NaCl}$ and glutardialdehyde dissolved in $0.1 \mathrm{M}$ acetic acid (HAc) supplemented with $0.25 \mathrm{~mm}$ sodium azide. Different $\mathrm{pH}$ (adjusted with sodium hydroxide), sodium chloride concentrations and incubation times were used to test the binding of chitosan. The remaining aldehydes were terminated by incubations for at least $4 \mathrm{~h}$ in $1 \mathrm{~m}$ ethanolamine adjusted to $\mathrm{pH} 5$ with HAc. One set of chitosan layers was also $N$-acetylated through incubation in $200 \mathrm{~mm}$ 1-ethyl-3-(3-diaminopropyl)carbodiimide (EDC) and $50 \mathrm{~mm} N$-hydroxysuccinimide (NHS) in $0.1 \mathrm{~m} \mathrm{HAc}$ at pH 5 over night.

Loose aggregates of glutardialdehyde crosslinked chitosan formed during the chitosan immobilization procedure were rinsed with HAc and water and incubated in ethanolamine, rinsed and incubated in NHS/EDC/HAc as above. The aggregates were freezing dried, grounded with $\mathrm{KBr}$ and made into pellets for the FTIR (Bruker IFS 48) chemical analysis.

As a positive complement activation control hydrophobic samples were adsorption coated with normal human IgG $(1 \mathrm{mg} / \mathrm{ml}, 30 \mathrm{~min}$, Gammaglobulin, Pharmacia \& UpJohn, Sweden). The hydrophilic Si samples were used as positive controls for contact activation of coagulation and the hydrophobic $\mathrm{Si}$ as negative controls (relatively low-activator of both the complement and coagulation systems).

\subsection{Serum, plasma and antibody incubations}

Veronal buffer (VB) was prepared from $3 \mathrm{~mm} 5,5^{\prime}$ dietylbarbituric acid, $2 \mathrm{~mm}$ of it's corresponding sodium salt and $145 \mathrm{~mm} \mathrm{NaCl}$. $\mathrm{VB}^{2+}$ buffer was prepared through the addition of $0.5 \mathrm{~mm} \mathrm{MgCl}_{2}$ and $0.15 \mathrm{~mm}$ $\mathrm{CaCl}_{2}$ to $\mathrm{VB}$. EGTA-serum was prepared by addition of $2.5 \mathrm{~mm} \mathrm{MgCl}$ and $10 \mathrm{~mm}$ ethylene glycol-bis(betaaminoethylether)- $N, N, N^{\prime}, N^{\prime}$-tetraacetic acid (EGTA) to serum that was diluted with VB buffer. Both the VB and $\mathrm{VB}^{2+}$ buffers were prepared from deionized and filtered water (Milli-Q, $18.2 \mathrm{M} \Omega \mathrm{cm}$ ), adjusted to $\mathrm{pH} 7.4$ and supplemented with $0.25 \mathrm{~mm}$ sodium azide.

The above modified surfaces were incubated in $67 \%$ normal human serum (pooled from two apparently healthy individuals) in $\mathrm{VB}^{2+}$ or VB/EGTA buffer for 5 or $60 \mathrm{~min}$ at $37^{\circ} \mathrm{C}$. After each incubation the samples were extensively rinsed in respective buffer and transferred to polyclonal antibody solutions (diluted 1:50 in $\mathrm{VB}^{2+}$ ) and incubated for $30 \mathrm{~min}$ at $22^{\circ} \mathrm{C}$. The antibodies were directed towards the following human antigens: immunoglobulin $\mathrm{G}(\mathrm{IgG})$, complement factors 1q, 3c and $3 \mathrm{~d}(\mathrm{C} 1 \mathrm{q}, \mathrm{C} 3 \mathrm{c}$ and $\mathrm{C} 3 \mathrm{~d})$ and human serum albumin (HSA) (Dako, Denmark), and properdin (prop), high molecular weight kininogen (HMWK), and coagulation factor XII (FXII) and prekallikrein (PKK) (Nordic Immunology, the Netherlands).

Similar experiments were performed with $5 \mathrm{~min}$ incubations of the surfaces in $67 \%$ heparinized plasma in $\mathrm{VB}^{2+}$ at $37^{\circ} \mathrm{C}$, followed by incubation in solutions of polyclonal antibodies towards fibrinogen and von Willebrand Factor (vWF) (Dako, Denmark). All samples were rinsed in respective buffer before and after each incubation.

\subsection{Null ellipsometry}

The samples were rinsed with deionized water, blown dry with nitrogen and measured at three locations in air with a Rudolph Research AutoEL III bench null ellipsometer at $632.8 \mathrm{~nm}$ at $70^{\circ}$ angle of incidence and one zone. The thicknesses of the adsorbed films were calculated using the built-in software assuming a film refractive index $N_{\text {film }}=1.5$ and a silicon substrate refractive index $N_{\text {substrate }}=3.858-0.018 i$. The surface protein concentration, $\Gamma\left(\mu \mathrm{g} / \mathrm{cm}^{2}\right)$, was calculated according to the one component model for air measurements using $M / A=4.14$ where $M=$ molar mass $(\mathrm{g} / \mathrm{mol})$ and $A=$ molar refractivity $\left(\mathrm{cm}^{3} / \mathrm{mol}\right)$ as outlined by Cuypers [7].

\subsection{Atomic force microscopy (AFM)}

A NanoScope IIIa (Digital Instruments, USA) AFM was run in the tapping mode ${ }^{\mathrm{TM}}$. The surface roughness $\left(S_{\mathrm{q}}\right)$ before and after chitosan depositions were calculated with the built-in instrument software on images with $5 \mu \mathrm{m}$ scan size after a third degree plane fit.

\subsection{Statistical evaluation}

The adsorbed amounts of chitosan, serum and antibodies were tested using the Student's $t$-test against the null hypothesis of no adsorption. Adsorbed amounts significantly $(\alpha=0.05)$ above zero are marked with an asterisk $\left(^{*}\right)$ in the graphs. The average depositions and standard errors of means are displayed in the graphs. The chitosan immobilization experiments were performed in triplicate, the serum and antibody experiments 6 times and the plasma and antibody experiments 4 times.

\section{Results and discussion}

\subsection{Chitosan films on silicon}

Because of the large extent of hydrogen bonding in saccharide polymers their FTIR spectra become difficult to interpret. In our study, the interpretation was focused on the differences between the differently treated 


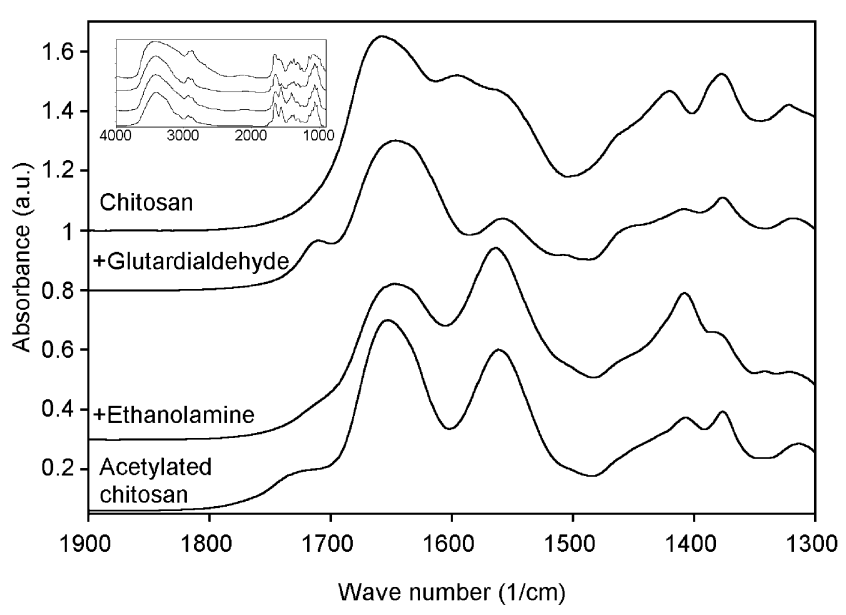

Fig. 1. FTIR spectra of chitosan before and after acetylation. Most vibrational information regarding the effects of the chemical treatments was in this study found in the wave number range 1800-1300/ $\mathrm{cm}$. The inset is the full spectra from 4000 to $1000 / \mathrm{cm}$.

chitosan samples in the spectral range $1800-1300 / \mathrm{cm}$ (Fig. 1). The amide I (approx. 1650/cm) and amide II (approx. 1560/cm) peaks were present in all samples although at different proportions and at peak positions depending on the chemical treatments. The peak at $1710-1720 / \mathrm{cm}$ probably originates from aldehyde groups after the glutardialdehyde treatment. This peak disappeared after ethanolamine incubation, as expected if the aldehydes react with amines. The peak reappeared after an NHS/EDC/HAc incubation since a similar vibration can also be found in ketones. The decrease of the $1596 / \mathrm{cm}$ peak after glutardialdehyde incubations may be due to a decreased amount of primary amines. The increase of the $1380 / \mathrm{cm}$ peak after an NHS/EDC/ HAc incubation may be due to an increase in the acetyl methyl content. The relative increase of the amide I compared to amide II band after incubation in EDC/ NHS/HAc also supports the hypothesis of an increased acetylation, since the amide $\mathrm{I}$ band $(\mathrm{C}=\mathrm{O}$ stretch $)$ is normally stronger than the amide II band.

The amount of APTES bound chitosan increased with increasing $\mathrm{NaCl}$ concentration, $\mathrm{pH}$ and time (Figs. 2A and $\mathrm{B})$. The results are in accordance with previous studies on the gelation of the chitosan-glutardialdehyde system that demonstrated a decrease in the gelation time with increasing $\mathrm{NaCl}$, chitosan and glutardialdehyde concentrations $[8,9]$. After $60 \mathrm{~min}$ of incubation in $0.4 \mathrm{mg} / \mathrm{ml}$ chitosan, $1 \%$ glutardialdehyde and $1 \mathrm{~m} \mathrm{NaCl}$ approximately $10 \mathrm{~nm}$ thick layers of chitosan remained firmly bound to the APTES surfaces (Fig. 2B). The chitosan was successfully immobilized at $\mathrm{pH} 4.5$ and 5 but not at pH 3 and 4 (Fig. 2A). The coupling to APTES surfaces took several hours to complete although most of the deposition occurred within the first hour (Fig. 2B). This is in contrast to a recent study that indicated a chitosan glutardialdehyde crosslinking in
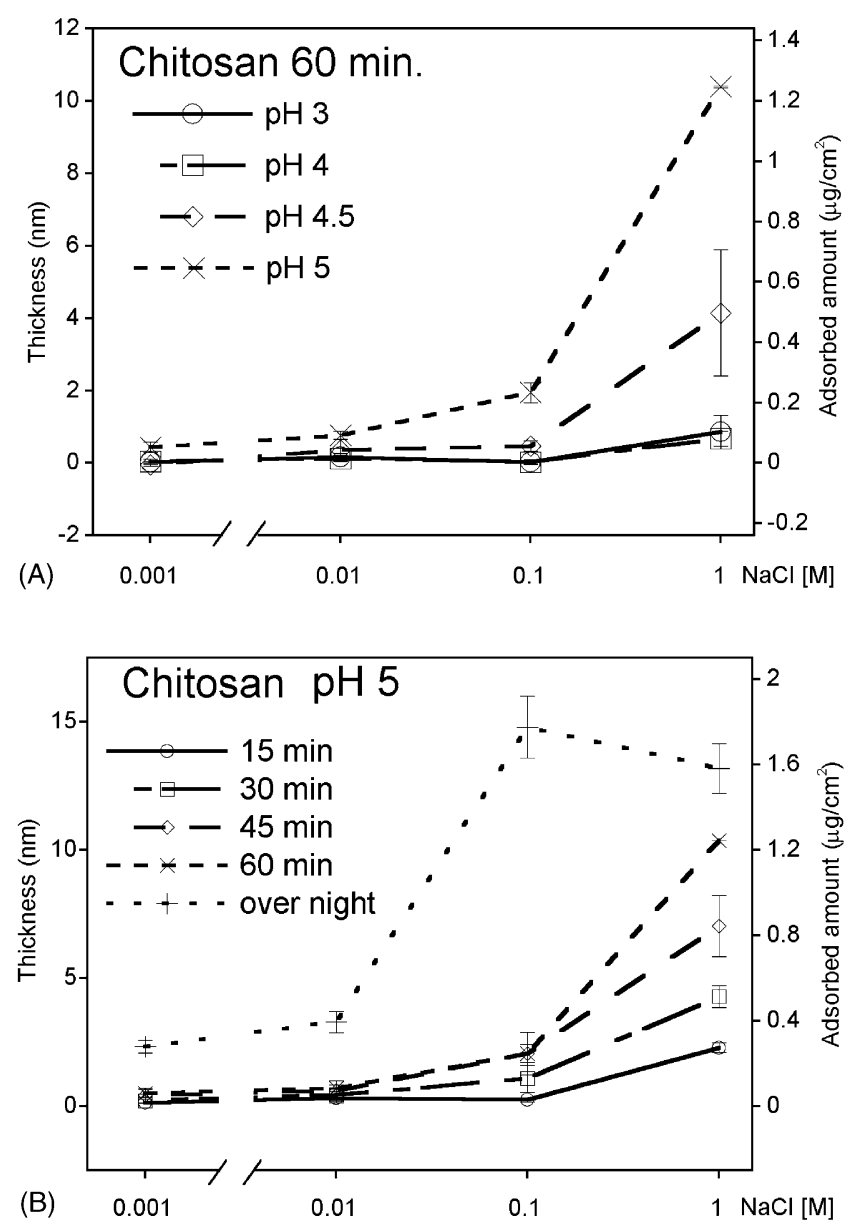

Fig. 2. (A) The average chitosan layer thickness on APTES surfaces at varying $\mathrm{pH}$ (adjusted with $\mathrm{NaOH}$ ) and $\mathrm{NaCl}$ concentrations. The surfaces were incubated for $60 \mathrm{~min}$ in $0.4 \mathrm{mg} / \mathrm{ml}$ chitosan and $1 \mathrm{wt} \%$ glutardialdehyde dissolved in 0.1 м HAc. (B) The average chitosan layer thickness at increasing $\mathrm{NaCl}$ concentrations and incubation times. The surfaces were incubated in $0.4 \mathrm{mg} / \mathrm{ml}$ chitosan and $1 \mathrm{wt} \%$ glutardialdehyde dissolved in $0.1 \mathrm{~m} \mathrm{HAc}$ that was adjusted to $\mathrm{pH} 5$ with $\mathrm{NaOH}$.

less than an hour for completion at $\mathrm{pH} 3$ and 4 [10]. A further increase in the chitosan and glutardialdehyde concentrations or a prolonged incubation time increased the deposition although the layer became then unevenly distributed. In extreme cases the average ellipsometric thickness was in the range between $20 \mathrm{~nm}$ to several hundreds of $\mathrm{nm}$ at different spots on the same sample. Since the chitosan layers were to be studied with serum and antibody solutions they needed to be even with an acceptable thickness variation of approximately $1 \mathrm{~nm}$. Hence most of the prepared chitosan films were prepared to about $10 \mathrm{~nm}$ thickness and with thickness variation of less than $10 \%$.

The stability of the covalent binding between chitosan and the glutardialdehyde activated APTES coated surface was tested by sonication of the chitosan coated surfaces in $0.1 \mathrm{~m} \mathrm{HAc}$ for $10 \mathrm{~min}$. No significant (less than $5 \%$ ) loss of material was observed. 
Alternating incubations of APTES coated samples in either chitosan or glutardialdehyde in $0.1 \mathrm{~m}$ HAc resulted in less than $0.5 \mathrm{~nm}$ thickness additions per cycle to the APTES surfaces irrespective of the incubation time, $\mathrm{pH}$ or $\mathrm{NaCl}$ concentration. Attempts were also made to cover the $\mathrm{Si}$ samples with chitosan by incubations in dilute chitosan solutions $(1 \mu \mathrm{g} / \mathrm{ml}-1 \mathrm{mg} /$ $\mathrm{ml}$ ) in $0.1 \mathrm{~m} \mathrm{HAc}$ followed by evaporation of the solvent, although such coatings became very rough and not appropriate for our purposes.

It is a drawback in bio-applications to use the cytotoxic glutardialdehyde [11] for immobilization purposes. However, the termination of the remaining aldehydes with ethanolamine is feasible and minimizes the problems with the reactive residues during tissue contact, in case such surfaces were implanted.

The ellipsometric thickness determination is an average over the ca. $0.6 \mathrm{~mm}^{2}$ laser spot area, and hence the more detailed topography of the chitosan layers was determined by AFM. The data indicated a fairly high surface roughness, $S_{\mathrm{q}}=5 \mathrm{~nm}$, compared to the average layer thickness of $10 \mathrm{~nm}$. In comparison, the APTES coated surfaces had a surface roughness of $S_{\mathrm{q}}=0.5 \mathrm{~nm}$. However, as the surfaces were completely coated with chitosan and as null ellipsometry is an averaging method for the determination of film thicknesses the surface roughness was no problem during the protein deposition measurements.

\subsection{Serum and antibody depositions}

The serum and antibody depositions in Figs. 3A-E show the positive and negative complement and contact activation controls for the investigated chitosan coated surfaces shown in Figs. 4A-C.

\subsubsection{Complement}

Hydrophobic silicon is a low activator of both the complement and coagulation cascade systems (Fig. 3A). After serum incubation none of the intrinsic pathway of coagulation proteins were antibody detectable and only small amounts of anti-C3c was deposited. Notably, HSA was antibody detectable on hydrophobic silicon, indicating a low activation and hence additional protein deposition of the humoral systems. On activator surfaces on the other hand, the formed protein complexes often cover and thereby sterically hinder antibody detection of a previously adsorbed HSA.

One example of a strong classical pathway complement activator surface is $\operatorname{IgG}$ coated hydrophobic silicon [12] (Fig. 3B). Note especially both the high serum and high anti-C $3 \mathrm{c}$ deposition already after $5 \mathrm{~min}$ serum incubation. Through the chelation of $\mathrm{Ca}^{2+}$ with EGTA the classical pathway can be inhibited $[13,14]$ and the time delayed alternative pathway activation $[12,15]$ can be observed (Fig. 3C). The time delay of activation was indicated also by the detection of $\mathrm{Clq}$ to $\mathrm{IgG}$ after 5 min of EGTA-serum incubation but not otherwise. After the EGTA-serum incubation both the deposited amounts of serum and anti-C3c were low after 5 min and high after $60 \mathrm{~min}$ (Fig. 3C) [12,16]. This also explains the high anti-HSA binding on $\mathrm{IgG}$ coated surfaces after $5 \mathrm{~min}$ of EGTA-serum incubation and low after $60 \mathrm{~min}$ (Fig. 3C).

Observe also that the increase in the deposition of anti-properdin indicates the presence of surface bound, functional and stabilized C3-convertases [17] of the alternative pathway [12] (see e.g. Fig. 3B). Furthermore, a low serum, anti-C3c and anti-properdin deposition after $5 \mathrm{~min}$ serum incubation but high of these three after $60 \mathrm{~min}$ of incubation strongly indicate an alternative pathway of complement activation (Fig. 3C). On surfaces that activate complement and where the inhibition of complement occurs also the presence of $\mathrm{C} 3 \mathrm{~d}$, a degradation product of $\mathrm{C} 3 \mathrm{~b}$ is expected. $\mathrm{C} 3 \mathrm{~b}$ is suggested to possess the ability to bind covalently to surface nucleophiles $[18,19]$ such as the amine terminated APTES that is a weak alternative pathway activator [20] (Fig. 3D) as can be seen from the low depositions of serum and antibodies compared to that on the IgG coated surfaces after EGTA serum incubations (Fig. 3C).

Relatively large amounts of serum proteins adsorbed to chitosan after $5 \mathrm{~min}$ of incubation (Fig. $4 \mathrm{~A}$ and B) and this is often indicative of a complement activator surface [6,12,16], cf. Fig. 3D. However, only small amounts of anti-C3c bound to the serum incubated chitosan film and the anti-properdin deposition was negligible, indicating no or a rapidly inhibited complement activation in spite of a low but still detectable, and previously not observed deposition of anti-IgG. In contrast, no anti-IgG deposition was observed onto the APTES coated surfaces after serum incubations (Fig. 3D).

When the chitosan layer was charge neutralized through the addition of acetyl groups to amines the films became strong activators of the alternative pathway of complement (Fig. 4C-cf. Fig. 3B). This suggests a strong electrostatic interaction between the more positively charged (deacetylated) chitosan and many blood proteins carrying a net negative charge at $\mathrm{pH}$ 7.4. Tentatively such proteins block or inhibit the activation of complement. Recent studies show that the degree of chitosan deacetylation is important for its complement activation properties in vivo and in vitro $[4,21]$. One of the studies performed in dogs indicated that chitin and chitosan activate the alternative pathway of complement as effectively as zymosan [4], a well known alternative pathway of complement activator. It was also shown in vitro that the activation of macrophages depended on the degree of deacetylation and substitution of chitosan [22] and that GlcNAc was more efficient for macro- 

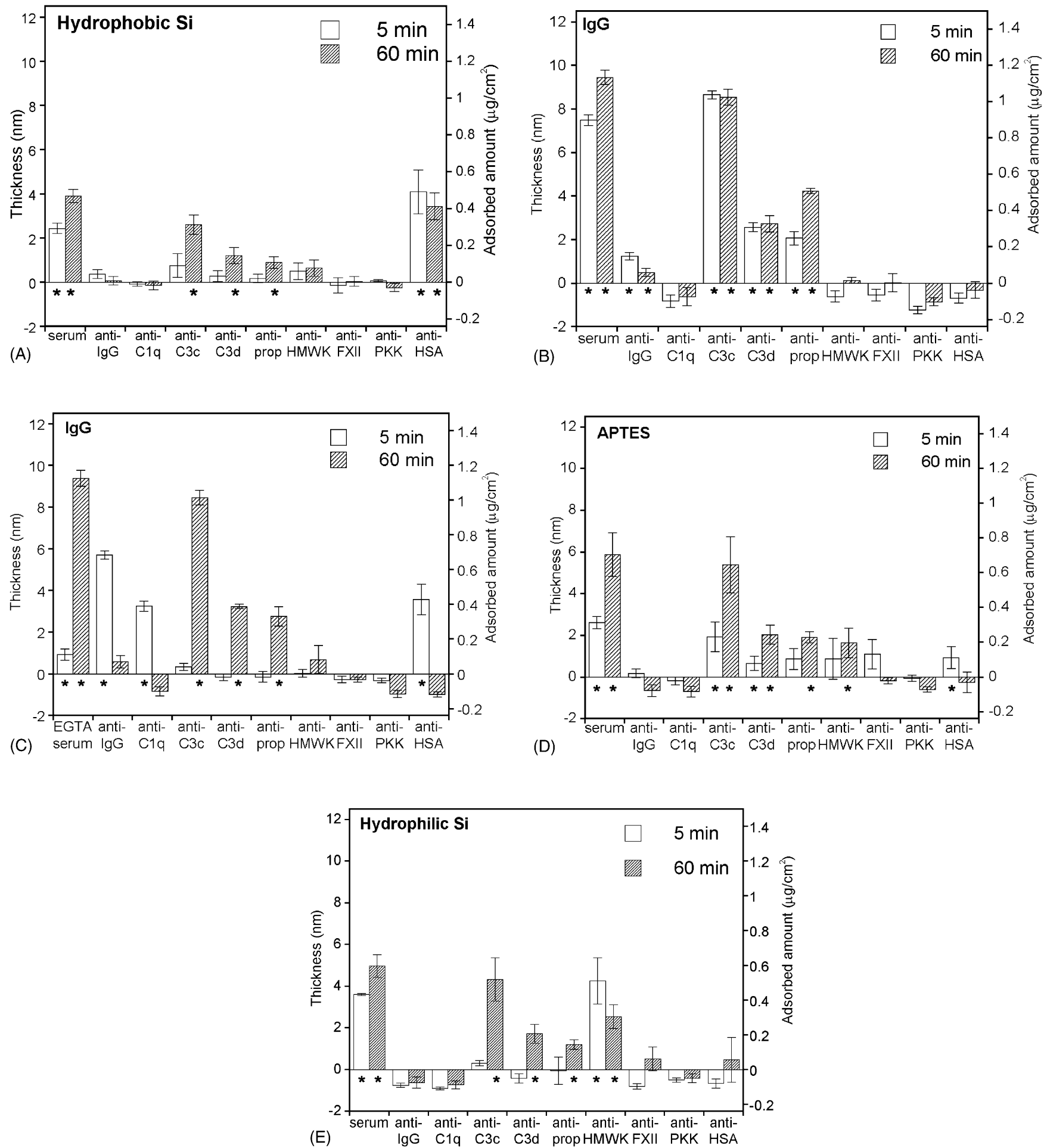

Fig. 3. (A) Normal serum (5 and 60 min incubation times) and subsequent net antibody depositions to hydrophobic silicon. This is a negative control for the activation of the intrinsic pathway of coagulation and a weak complement activator. Significant $(p<0.05)$ depositions are marked with an asterisk $(*)$. (B) Normal serum and subsequent net antibody depositions to IgG coated hydrophobic silicon. The surface is a strong classical complement pathway activator and a negative control for contact activation of coagulation. (C) EGTA-serum and subsequent net antibody depositions to IgG coated hydrophobic silicon. The system shows a typical alternative pathway complement activation and is a negative control for contact activation of coagulation. (D) Normal serum and subsequent net antibody depositions to APTES coated silicon surfaces. The surface is a positive control for a relatively weak alternative complement pathway activation by amine containing surfaces, and a negative control for contact activation of coagulation. (E) Normal serum and subsequent net antibody depositions to hydrophilic silicon. This surface is a positive control for contact activation of coagulation and a weak complement activator. Observe the relatively high binding of anti-HMWK after the serum incubations. 

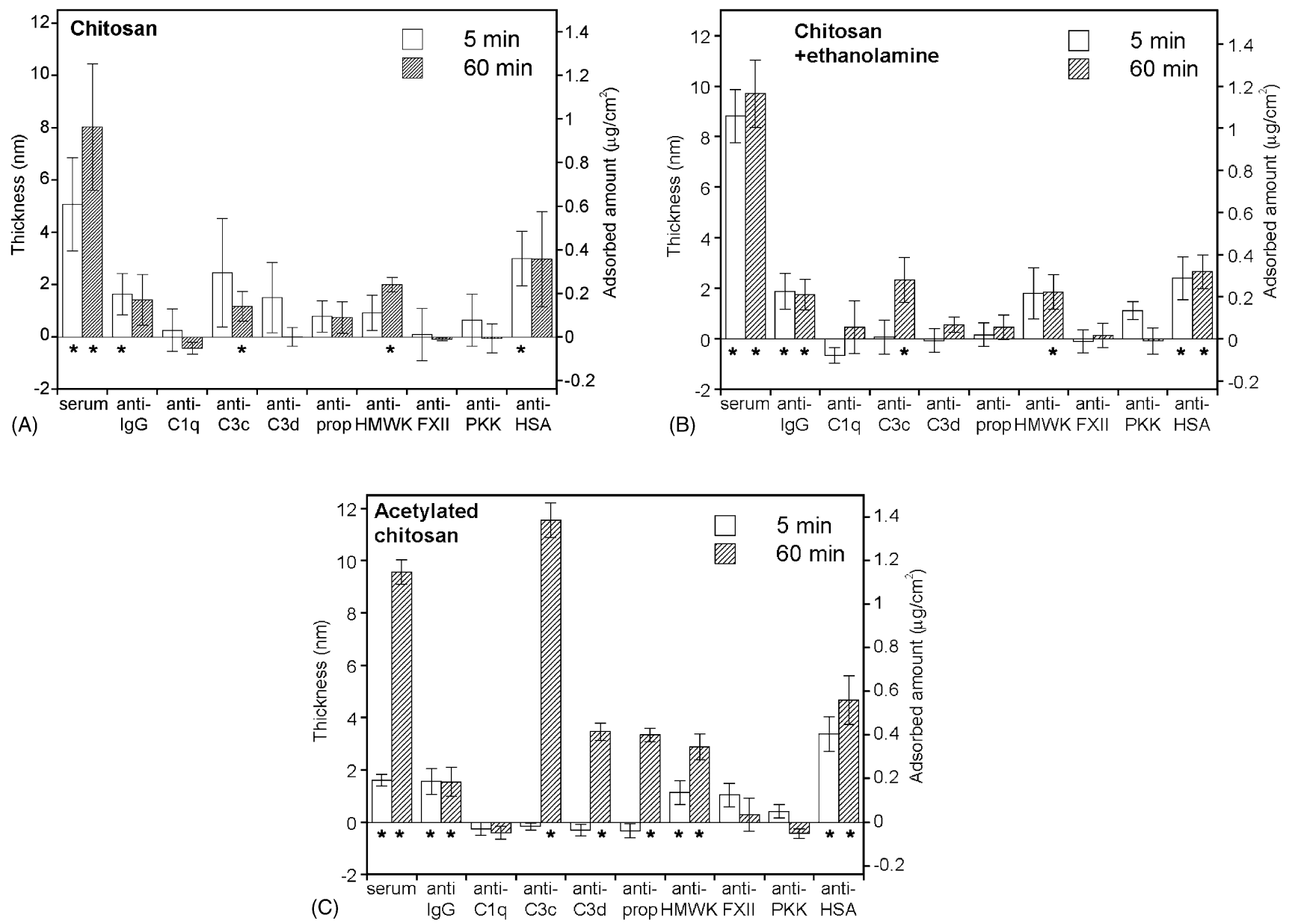

Fig. 4. (A) Normal serum (5 and 60 min incubation times) and subsequent net antibody depositions to chitosan that was immobilized to APTES coated surfaces by glutardialdehyde. Significant $(p<0.05)$ protein depositions are marked with an asterisk $\left(^{*}\right)$. (B) Normal serum and subsequent net antibody depositions onto chitosan that was coupled to APTES coated surfaces by glutardialdehyde. The residual aldehydes were terminated by an overnight incubation $1 \mathrm{~m}$ ethanolamine at $\mathrm{pH}$ 5. (C) Normal serum and subsequent net antibody deposition onto acetylated chitosan. This surface was prepared from chitosan that was coupled to APTES coated surfaces by glutardialdehyde. The residual aldehydes were terminated by an over night incubation $1 \mathrm{M}$ ethanolamine at $\mathrm{pH}$ 5. The residual amines were acetylated through overnight incubation in $200 \mathrm{~mm}$ EDC, $50 \mathrm{~mm}$ NHS and $100 \mathrm{~mm}$ HAc at $\mathrm{pH} 5$.

phage activation than GlcN in vivo and in vitro [23]. Since macrophages express complement receptors and become activated by complement [24], these findings support the present results where chitosan (Fig. 4A-B) (containing mostly GlcN) did not the activate complement system whereas the acetylated form (containing more GlcNAc) was a strong alternative pathway of complement activator (Fig. 4C).

\subsubsection{Contact activation}

Negatively charged surfaces that activate the intrinsic pathway of coagulation (contact activation) bind relatively large amounts of anti-HMWK after serum (or plasma) incubations, as observed on hydrophilic silicon (Fig. 3E) but not on the hydrophobic $\mathrm{Si}$ or the IgG coated samples (Fig. 3A-C). As expected, only small amounts of anti-HMWK deposited onto the positively charged APTES surfaces (Fig. 3D). On activator surface also anti-FXII and anti-PKK deposit but these were not detectable in this study, perhaps due to the use of serum instead of plasma or whole blood in our in vitro experiments. The anti-HMWK binding contradicts a previous study where HMWK did not adsorb to negatively charged surfaces after incubation in FXII deficient plasma and where also the HMWK adsorption was lowered in PKK deficient plasma [25]. Thus, the low the deposition of anti-HMWK in the present study onto the three types of chitosan coatings is therefore surprising (Fig. 4A-C). Since all three contact activation proteins (HMWK, PKK and FXII) were concurrently not antibody detectable, chitosan did apparently not activate the intrinsic pathway of coagulation. The results are more in line with other studies indicating that chitosan triggers coagulation without the activation of the intrinsic pathway $[5,26,27]$. Maybe the deposition of fibrinogen from plasma and concomitant binding of platelets accounts for this activation, see Section 3.3. The activation was, however, 


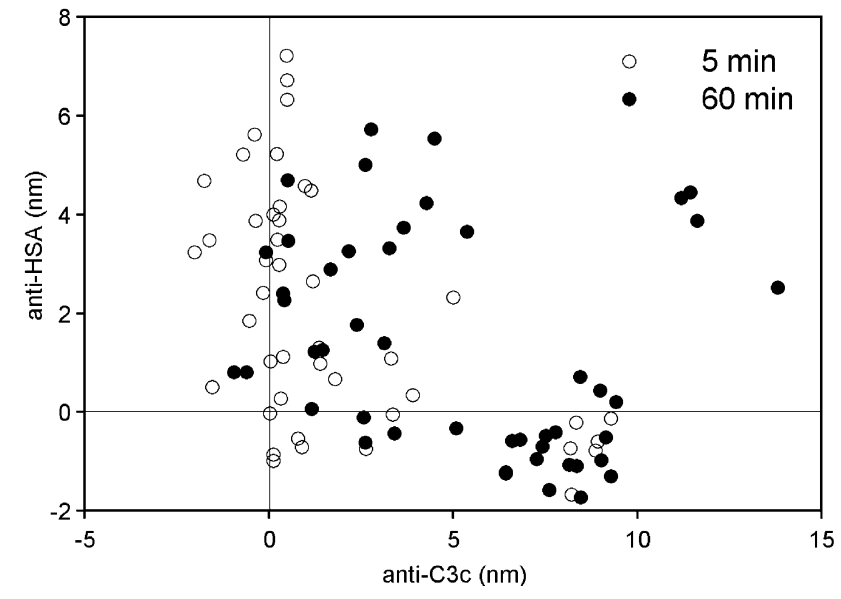

Fig. 5. Relationship between of anti-C3c and anti-properdin depositions after serum incubations of the different surfaces in the present study. Three outliers were omitted.

slower than that observed on glass [28], the positive control for intrinsic pathway activation. Another study indicated that chitosan induced blood coagulation in vitro was independent on FVII but required FXI and FXII [29]. Also, it has been shown that coagulation proceeds faster in whole blood when chitosan is introduced and even minute amounts can agglutinate red blood cells [26]. Chitosan was therefore proposed for use as a hemostatic agent prior to that study [5,27].

\subsubsection{Anti-HSA and anti-properdin vs. anti-C3c deposition}

Relatively large amounts of anti-HSA deposited to the chitosan, hydrophobic Si and IgG (5 min in EGTA serum only) coated samples after serum incubations. The latter two cases indicates that anti-HSA binds to non-activating surfaces, thus implying that chitosan also is a non- or low-activator. In order to further analyze this aspect, the deposition of anti-HSA and antiproperdin were plotted vs. anti-C3c deposition (Fig. 5) for the studied surfaces.

Overall, a large anti-C3c deposition was paralleled of large anti-properdin deposition (not shown) indicating that alternative pathway of complement $\mathrm{C} 3$-convertases become stabilized and increase in amount with time on activator surfaces.

In contrast, anti-C $3 \mathrm{c}$ deposition was high when antiHSA deposition was low, but when anti-C3c deposition was low anti-HSA deposition was not necessarily high (Fig. 5). One exception was the acetylated chitosan where large amounts of anti-HSA deposited after $60 \mathrm{~min}$ of serum incubation even though it is a relatively strong alternative pathway of complement activator with a high anti-C3c deposition. This suggests that when both anti-C3c and anti-HSA depositions were low other proteins adsorbed and sterically hindered their detection on the surfaces.

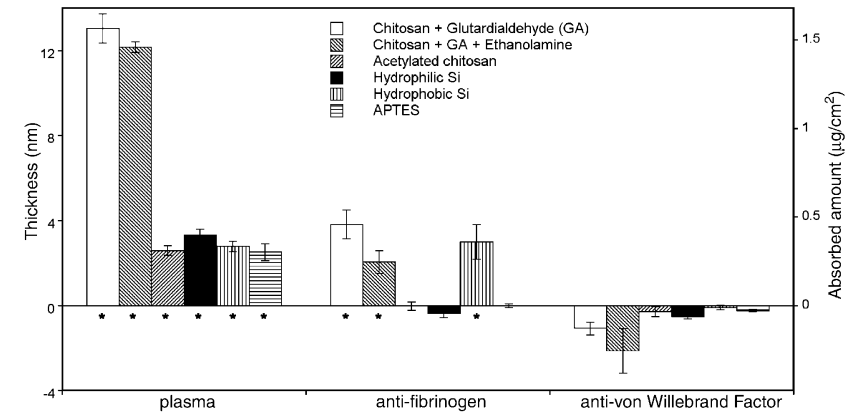

Fig. 6. Deposition of heparinized plasma (after $5 \mathrm{~min}$ incubation at $37^{\circ} \mathrm{C}$ ) and the subsequent net anti-fibrinogen and anti-von Willebrand factor bindings onto the differently treated chitosan and control surfaces.

\subsection{Plasma and antibody depositions}

After $5 \mathrm{~min}$ of incubation in heparin plasma fibrinogen was antibody detectable on the positively charged chitosan but not on acetylated chitosan (Fig. 6). This may explain previous findings that chitosan activates the coagulation of blood $[5,26,27]$ by offering binding sites to platelets that in turn trigger the primary hemostasis by binding via GPIIb/IIIa to the adsorbed fibrinogen $[30,31]$. The degree of binding and activation depends, however, on the conformation of the adsorbed fibrinogen [32]. Also, the platelets need to become activated e.g. by thrombin before the GPIIb/IIIa receptor is able to bind to fibrinogen [33], which may happen e.g. when the alternative pathway of complement $\mathrm{C} 3$ convertases cleave prothrombin to thrombin $[34,35]$. The second important platelet activator protein, von Willebrand Factor (vWF) was on the other hand not antibody detectable on any of the surfaces under study.

\section{Summary}

Thin chitosan films that were prepared by glutardialdehyde crosslinking of chitosan to APTES coated samples appeared to be weak activators of the alternative pathway of complement and the intrinsic pathway of coagulation. However, acetylation turned the chitosan coating into a strong alternative pathway activator. Large amounts of fibrinogen and other plasma proteins bound to chitosan but not to acetylated chitosan, a fact that may explain the previously observed procoagulant behavior of chitosan.

\section{Acknowledgements}

This research was supported by the Biocompatible Materials Program and Graduate Research School Forum Scientum, both funded by the Swedish Foundation for Strategic Research (SSF). We would also like to 
thank Mattias Östblom for valuable discussions regarding the interpretation of the IR spectra.

\section{References}

[1] Klokkevold PR, Vandemark L, Kenney EB, Bernard GW. Osteogenesis enhanced by chitosan (poly- $N$-acetyl glucosaminoglycan) in vitro. J Peridont 1996;67:1170-5.

[2] Muzzarelli RA, Mattioli-Belmonte M, Pugnaloni A, Biagini G. Biochemistry, histology and clinical uses of chitins and chitosans in wound healing. In: Jollès P, Muzzarelli RAA, editors. Chitin and Chitinases. Basel: Birkhäuser Verlag, 1999. p. 251-64.

[3] Peter MG. Applications and environmental aspects of chitin and chitosan. JMS Pure Appl Chem 1995;a32:629-40.

[4] Minami S, Suzuki H, Okamoto Y, Fujinaga T, Shigemasa Y. Chitin and chitosan activate complement via the alternative pathway. Carbohydr Polym 1998;36:151-5.

[5] Brandenberg G, Leibrock LG, Shuman R, Malette WG, Quigley H. Chitosan: a new topical hemostatic agent for diffuse capillary bleeding in brain tissue. Neurosurgery 1984;15:9-13.

[6] Vroman L, Adams AL. Identification of rapid changes at plasmasolid interfaces. J Biomed Mater Res 1969;3:43-67.

[7] Cuypers PA, Corsel JW, Janssen MP, Kop JMM, Hermens WT, Hemker HC. The adsorption of prothrombin to phosphatidylserine multilayers quantified by ellipsometry. J Biol Chem 1983;258:2426-31.

[8] Roberts GAF, Taylor KE. Chitosan gels, 3 The formation of gels by reaction of chitosan with glutaraldehyde. Makromolecular Chem 1989;190:951-60.

[9] Moore GK, Roberts AF. Chitosan gels: 1. Study of reaction variables. Int J Biol Macromol 1980;2:73-7.

[10] Monteiro Jr OAC, Airoldi C. Some studies of crosslinking chitosan-glutaraldehyde interaction in a homogenous. Int J Biol Macromol 1999;26:119-28.

[11] Speer DP, Chvapil M, Eskelson CD, Ulreich J. Biological effects of residual glutaraldehyde in glutaraldehyde-tanned collagen biomaterials. J Biomed Mater Res 1980;14:753-64.

[12] Tengvall P, Askendal A, Lundström I. Complement activation by IgG immobilized on methylated silicon. J Biomed Mater Res 1996;31:305-12.

[13] Reid KBM. Classical pathway of activation. In: Rother K, Till GO, Hänsch GM, editors. The complement system. Berlin: Springer, 1998. p. 68-86.

[14] Levine L, Cowan KM, Osler AG, Mayer MM. The role of calcium and magnesium ions in complement fixation and immune hemolysis. II. The essential role of calcium in complement fixation. J Immunol 1953;71:367-73.

[15] Forsgren A, Mclean RH, Michael AF, Quie PG. Studies of the alternate pathway in chelated serum. J Lab Clin Med 1975;85:904-12.

[16] Tengvall P, Askendal A, Lundström I. Temporal studies on the deposition of complement on human colostrum IgA and serum IgG immobilized on methylated silicon. J Biomed Mater Res 1997;35:81-92.

[17] Fearon DT, Austen KF. Properdin: binding to C3b and stabilization of the C3b-dependent C3 convertase. J Exp Med $1975 ; 142: 856-63$.
[18] Law SK, Lichtenberg NA, Levine RP. Evidence for an ester linkage between the labile binding site of $\mathrm{C} 3 \mathrm{~b}$ and receptive surfaces. J Immunol 1979;123:1388-94.

[19] Pangburn MK, Schreiber RD, Muller-Eberhard HJ. Formation of the initial $\mathrm{C} 3$ convertase of the alternative complement pathway. Acquisition of C3b-like activities by spontaneous hydrolysis of the putative thioester in native C3. J Exp Med 1981;154:856-67.

[20] Mold C. Effect of membrane phospholipids on activation of the alternative complement pathway. J Immunol 1989; 143:1663-8.

[21] Suzuki Y, Okamoto Y, Morimoto SH, Saimoto H, Tanioka S-I, Shigemasa Y, Minami S. Influence of physico-chemical properties of chitin and chitosan on complement activation. Carbohydr Polym 2000;42:307-10.

[22] Nishimura K, Nishimura S, Nishi N, Saiki I, Tokura S, Azuma I. Immunological activity of chitin and its derivatives. Vaccine 1984;2:93-9.

[23] Peluso G, Petillo O, Ranieri M, Santin M, Ambrosio L, Calabro D, Avallone B, Balsamo G. Chitosan-mediated stimulation of macrophage function. Biomaterials 1994;15:1215-20.

[24] Greenberg S. Biology of phagocytosis. In: Gallin JI, Snyderman $\mathrm{R}$, editors. Inflammation: basic principles and clinical correlates. Philadelphia: Lippincott Williams \& Wilkins, 1999. p. 681-701.

[25] Scott C, Silver L, Schapira M, Colman R. Cleavage of human high molecular weight kininogen markedly enhances its coagulant activity. Evidence that this molecule exists as a procofactor. J Clin Invest 1984;73:954-62.

[26] Rao SB, Sharma CP. Use of chitosan as a biomaterial: studies on its safety and hemostatic potential. J Biomed Mater Res 1997;34:21-8.

[27] Malette WG, Quigley HJ, Gaines RD, Johnson ND, Rainer WG. Chitosan: a new hemostatic. Ann Thor Surg 1983;36:55-8.

[28] Dutkiewicz J, Szosland L, Kucharska M, Judkiewicz L, Ciszewski R. Structure-bioactivity relationship of chitin derivatives. Part I: The effect of solid chitin derivatives on blood coagulation. J Bioact Compat Polym 1990;5:293-304.

[29] Pugnaloni A, Lai G, Ravaglia F, Santori M, Piciotti D, Sprovieri G, Muzzarelli RAA, Emanuelli M, Sapelli P, Baldassarre V. Evaluation of chitosan effects on the hemostatic process. Clin Lab (Rome) 1986;10:151-4.

[30] Hantgan R, Nichols W, Ruggeri Z. Von Willebrand factor competes with fibrin for occupancy of GPIIb:IIIa on thrombinstimulated platelets. Blood 1990;75:889-94.

[31] Park K, Mao FW, Park H. The minimum surface fibrinogen concentration necessary for platelet activation on dimethyldichlorosilane-coated glass. J Biomed Mater Res 1991;25:407-20.

[32] Lindon JN, McManama G, Kushner L, Merrill EW, Salzman EW. Does the conformation of adsorbed fibrinogen dictate platelet interactions with artificial surfaces? Blood 1986;68: 355-62.

[33] Hantgan R, Taylor R, Lewis J. Platelets interact with fibrin only after activation. Blood 1985;65:1299-311.

[34] Hayashi K, Fukumura H, Yamamoto N. In vivo thrombus formation induced by complement activation on polymer surfaces. J Biomed Mater Res 1990;24:1385-95.

[35] Fair DS, Sundsmo JS, Schwartz BS, Edgington TS, MüllerEberhard HJ. Prothrombin activation by factor $\mathrm{B}(\mathrm{Bb})$ of the alternative complement pathway. Thrombos Hemost 1981;46:301. 